Article

\title{
Larvicidal and Cytotoxic Potential of Squamocin on the Midgut of Aedes aegypti (Diptera: Culicidae)
}

Marilza S. Costa ${ }^{1}$, Jamile F. S. Cossolin ${ }^{1}$, Mônica J. B. Pereira ${ }^{2}$, Antônio E. G. Sant'Ana ${ }^{3}$, Milena D. Lima ${ }^{3}$, José C. Zanuncio ${ }^{4}$ and José Eduardo Serrão ${ }^{1, *}$

1 Laboratory of Cell Ultrastructure, Department of General Biology, Federal University of Viçosa, Viçosa 36570-000, Minas Gerais, Brazil; E-Mails: marilza.costa@ufv.br (M.S.C.); jamile.cossolin@ufv.br (J.F.S.C.)

2 Laboratory of Entomology, Research and Study Center of Agriculture and environment Development, University of Mato Grosso State; MT 358, Km 7, Jardim Aeroporto, Tangará da Serra 78300-000, Mato Grosso, Brazil; E-Mail: monica@unemat.br

3 Institute of Chemistry and Biotechnology, Federal University of Alagoas, Avenida Lourival Melo Mota, Tabuleiro do Martins, Maceió 57072-970, Alagoas, Brazil; E-Mails: aegs@qui.ufal.br (A.E.G.S.); miladuli@yahoo.com.br (M.D.L.)

4 Departament of Entomology, Federal University of de Viçosa, Viçosa 36570-000, Minas Gerais, Brazil; E-Mail: zanuncio@ufv.br

* Author to whom correspondence should be addressed; E-Mail: jeserrao@ufv.br; Tel.: +55-31-3899-1301; Fax: +55-31-3899-2549.

Received: 20 January 2014; in revised form: 28 February 2014 / Accepted: 11 March 2014 / Published: 26 March 2014

\begin{abstract}
Acetogenins are secondary metabolites exclusively produced by Annonaceae, which have antitumor, cytotoxic, and pesticide activities. In this study, we evaluated the larvicidal and cytotoxic effect of squamocin from Annona squamosa on Aedes aegypti (Diptera: Culicidae) midgut. The compound was solubilized in 2\% Tween 20 at 10, 20, 50, 80 and $100 \mathrm{ppm}$. The assay was conducted in a completely randomized design with four replications, each with 20 third-instar larvae. Larval mortality was assessed every hour until total mortality, and the data were subjected to Probit analysis. Cellular damage was evaluated every $30 \mathrm{~min}$ in groups comprising five larvae subjected to squamocin at 50 and $100 \mathrm{ppm}$ for $240 \mathrm{~min}$. The total larval mortality occurred after $360 \mathrm{~min}$ following application of 50, 80, and $100 \mathrm{ppm}$ squamocin, and $600 \mathrm{~min}$ after applying other concentrations with $\mathrm{LC}_{50}$ at $6.4 \mathrm{ppm}$. Both 50 and $100 \mathrm{ppm}$ of squamocin showed cytotoxic activity in the midgut epithelium of $A$. aegypti after 240 min with 50 ppm
\end{abstract}


resulting in midgut cells with light cytoplasm containing small vacuoles, whereas at $100 \mathrm{ppm}$ were found cells with cytoplasm highly vacuolated, damaged apical surface and cell protrusion toward the gut lumen. In conclusion, squamocin has the potential to control A. aegypti.

Keywords: acetogenin; Annonaceae; cell death; botanical insecticides; dengue

\section{Introduction}

Acetogenins are exclusive secondary metabolites of Annonaceae synthesized via acetic acid-polyketides derived from long-chain fatty acids with 35-39 carbon atoms [1]. These compounds are characterized by a long aliphatic chain with hydroxyl functional groups, and acetyl carbonyl and a terminal $\gamma$-lactone ring with 1-3 tetrahydrofuran (THF) rings [2].

Squamocin, also called anonin $\mathrm{I}$, is an acetogenin with 37 carbon atoms, $\alpha, \beta$-unsaturated $\gamma$-lactone ring, and adjacent bis-tetrahydrofuran (bis-THF) ring [3], and has been reported in Annona squamosa and Annona atemoia [4].

Acetogenins have cytotoxic, antitumor and pesticide activities [5], and act on cellular models by inhibiting mitochondrial respiration at complex I [6] and NADH: ubiquinone oxidoreductase thus blocking mitochondrial oxidative phosphorylation resulting in apoptosis [7].

These compounds are gut poisons and are particularly effective against chewing insects such as Lepidoptera and Leptinotarsa decemlineata (Say) 1824 (Coleoptera: Chrysomelidae) [8].

Annona squamosa has been noted to show lethal effect against insects, especially mosquitoes [9]. The crude extracts of Annona coriacea (species rich in aromatic acetogenins) have been observed to partially or totally disrupt midgut epithelial cells of $A$. aegypti [10]. However the use of crude extract does not indicate that the Annonaceae acetogenins cause these changes because plants of this family produce other secondary compounds toxic to insects, such as tannins, alkaloids and lectins [11].

The aim of this study was to evaluate the larvicidal and cytotoxic effect of the acetogenin, squamocin, on the larval midgut of the dengue vector Aedes aegypti.

\section{Results and Discussion}

After exposure to squamocin at concentrations of 50, 80, and $100 \mathrm{ppm}$ for $360 \mathrm{~min}$, the A. aegypti larvae mortality was $100 \%$. Furthermore, all the mosquito larvae died after $190 \mathrm{~min}$ of exposure to 10 and 20 ppm of squamocin. The $\mathrm{LC}_{50}$ was 6.4 ppm for $A$. aegypti larvae after $190 \mathrm{~min}$.

The acetogenin, squamocin, isolated from A. squamosa, at concentrations of 50-100 ppm, showed cytotoxic activity with gradual changes in the midgut epithelium of $A$. aegypti larvae from 120 min of exposure. The midgut epithelium exhibited a single layer of columnar cells lining the lumen in the control and insects exposed to squamocin at concentrations of 50 and $100 \mathrm{ppm}$ for 30 and $60 \mathrm{~min}$ (Figure 1). The central nucleus of these cells showed decondensed chromatin and an evident nucleolus, the cytoplasm presented some small vacuoles, the apical brush border was found along the entire midgut length, and a peritrophic membrane surrounded the gut content (Figure 2A,B). 
Figure 1. Photomicrograph of the midgut of Aedes aegypti third-instar larvae (Diptera: Culicidae) stained with hematoxyline and eosin (HE). Columnar cells (Co), central nucleus $(\mathrm{N})$, some cytoplasm vacuoles (v) and pink brush border (arrow) in the apical surface of the cells in larvae of controls group. $\mathrm{L}=$ lumen. Bar: $20 \mu \mathrm{m}$.

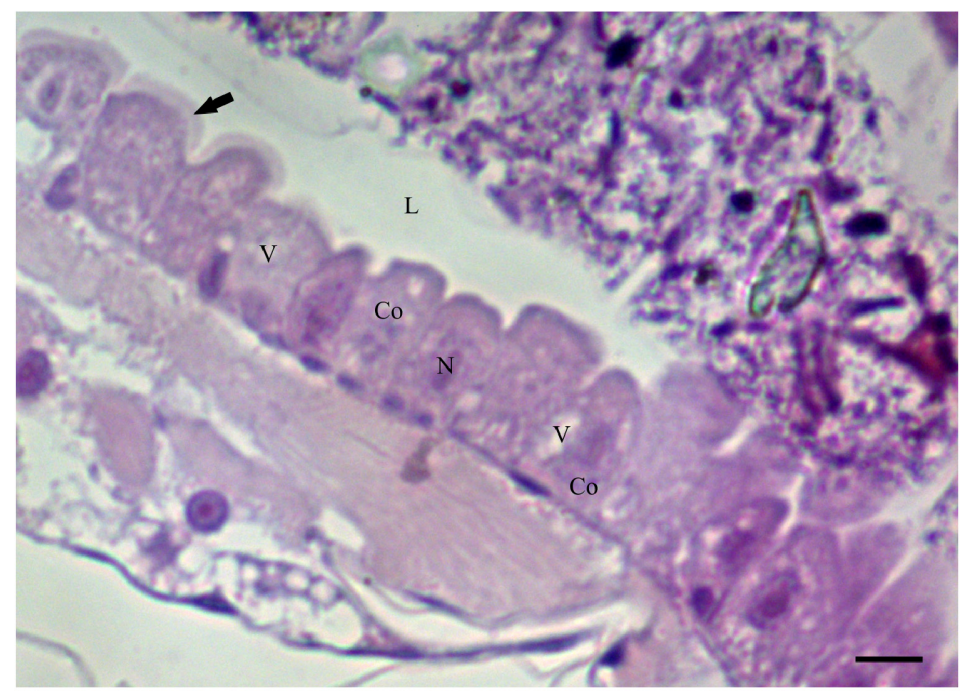

Figure 2. Photomicrograph of the midgut of Aedes aegypti third-instar larvae (Diptera: Culicidae) stained with HE. (A) Squamocin at $50 \mathrm{ppm}$ for $30 \mathrm{~min}$; (B) Squamocin in $50 \mathrm{ppm}$ for $60 \mathrm{~min}$. (L) lumen, (N) nucleus, (v) vacuoles, (arrow) brush border. Bars: $10 \mu \mathrm{m}$.
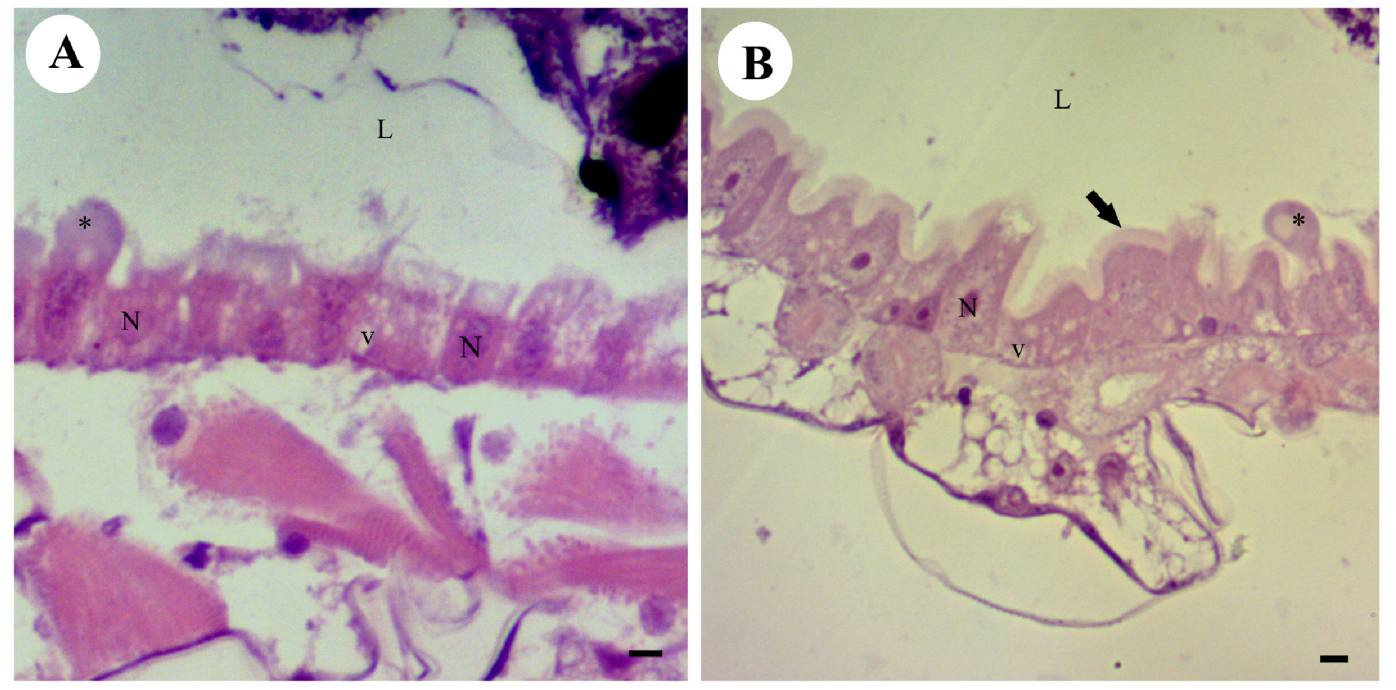

The A. aegypti larvae exposed to 50 and $100 \mathrm{ppm}$ of squamocin for 120 and 240 min showed midgut epithelium with cubic digestive cells, which had dilated apical surface, and the cytoplasm containing larger area of vacuolization (Figure 3A,B) than midgut cells in the control insects. 
Figure 3. Photomicrograph of the midgut of Aedes aegypti third-instar larvae (Diptera: Culicidae) stained with HE. (A) Squamocin in $50 \mathrm{ppm}$ for $120 \mathrm{~min}$ showing cubic cells (Cu) with central nuclei (N) and vacuolated cytoplasm (v); (B) Squamocin in 50 ppm for 240 min showing the cytoplasm with large vacuoles (v) and brush border with apparent damages (arrow) and cytoplasmic projections toward the lumen; (C) Squamocin in $100 \mathrm{ppm}$ for 120 and $240 \mathrm{~min}$ (D) showing large vacuoles (v) and brush border with apparent damage (arrow) and cytoplasmic projections (*) toward the lumen. Bars: $20 \mu \mathrm{m}$.
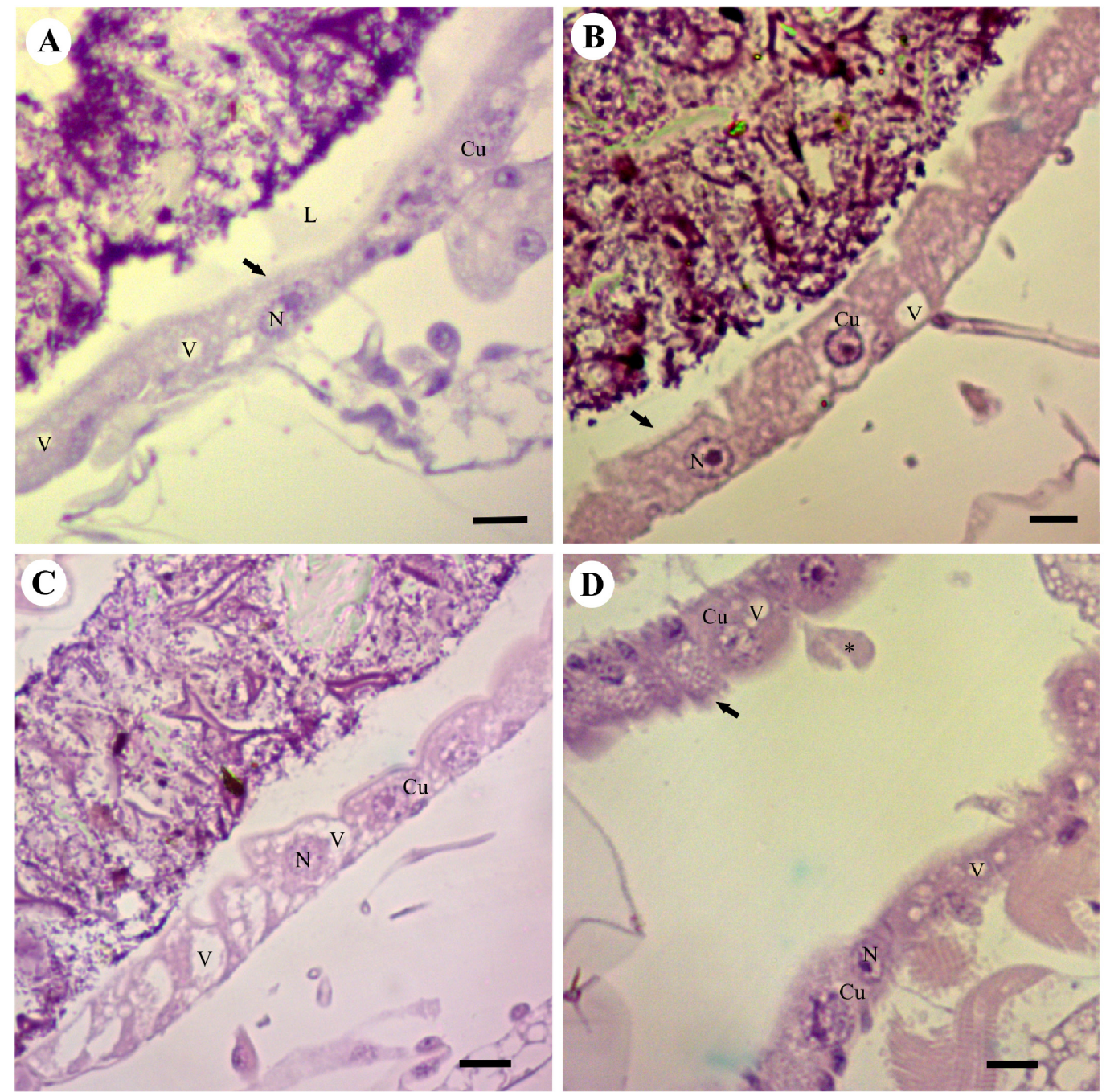

Following exposure to $100 \mathrm{ppm}$ of squamocin for $120 \mathrm{~min}$, the midgut of the A. aegypti larvae showed disruption of the peritrophic membrane and damage of the brush border (Figure 3C). After $240 \mathrm{~min}$ of exposure to $100 \mathrm{ppm}$ of squamocin, the cytoplasmic vacuoles occupied most of the digestive cells, the brush border was found in different degenerative stages, and the number of cells with apical cytoplasm projections into the midgut lumen was high (Figure 3D).

The larvicidal effect of squamocin at concentration of $10 \mathrm{ppm}$ on A. aegypti after 600 min of exposure (6.4 ppm $\mathrm{LC}_{50}$ ) indicated the potential use of this compound as an insecticide, similar to that reported against Plutella xylostella [12], Marcellus eurytides [13] Spodoptera littoralis, Leptinotarsa decemlineata, Myzus persicae [14], Oncopeltus fasciatus [15], and Spodoptera frugiperda [16]. 
The effect of squamocin from $A$. squamosa on $A$. aegypti larvae can be explained by the fact that this compound is a bis-THF adjacent acetogenin [2,17], which inhibits NADH: ubiquinone oxidoreductase, preventing electron transport in the mitochondrial complex I $[1,18]$. The electrons in the mitochondrial compex I prevent the production of ATP and cause the death of the insect by affecting cellular respiration [19-21].

Vacuolization and changes in the brush border of the midgut digestive cells of the $A$. aegypti larvae may indicate that these cells were dying, perhaps owing to the toxicity of squamocin, as described in Culex quinquefasciatus (Diptera: Culicidae) subjected to synthetic insecticides [22] and Spodoptera frugiperda (Lepidoptera: Noctuidae) treated with neem extract [23].

The change in the shape of midgut digestive cells from columnar to cubic in A. aegypti was firstly reported to have been caused by acetogenin. This change was not found in the midgut of the third-instar larvae of the A. aegypti not exposed to squamocin [24]. However, similar changes were observed in the A. aegypti larvae exposed to crude extracts of A. coriacea [10] and Derris urucu (Leguminosae) [25], of which the later has rotenone with action similar to that described for acetogenins [26].

The cytotoxic and larvicidal effects of squamocin on $A$. aegypti larvae might be attributed to the structure of the molecule. It has been reported that the acetogenins with adjacent bis-THF rings have high toxicity [3,27], which is favored by the polarity necessary for the cytotoxic activity of acetogenins [28] and might improve the interaction of these compounds with the targets within the cell [29]. The THF ring from squamocin may interact with the phosphate group from the lipid plasma membrane [30,31], causing irreversible damages to the structures and functions of the biological membrane [32], as observed in the midgut digestive cells the of A. aegypti larvae.

\section{Experimental Section}

The A. aegypti larvae, reared at $28 \pm 3{ }^{\circ} \mathrm{C}, 70 \% \pm 10 \%$ relative humidity and $12 \mathrm{~h}$ photophase, were obtained from the Laboratory of Entomology, University of Mato Grosso State, campus Tangará da Serra.

The squamocin was acquired from the Research Laboratory of Natural Products Chemistry, Federal University of Alagoas, by using high performance liquid chromatography and nuclear magnetic resonance at $97 \%$ of purity and solubilized in 2\% Tween 20 in concentrations of 10, 20, 50, 80 and $100 \mathrm{ppm}$.

The larvicidal bioassay was conducted in a completely randomized design with four replications. Each group comprised $20 \mathrm{~A}$. aegypti third-instar larvae, which were kept in a $25 \mathrm{~mL}$ glass vial. The larval mortality was assessed every hour from the start of the bioassay until total mortality. The data were submitted to Probit analysis.

The cytotoxic action of squamocin at concentrations of 50 and $100 \mathrm{ppm}$ was evaluated in third-instar larvae subjected to this compound in a $25 \mathrm{~mL}$ vial.

Five $A$. aegypti larvae were removed every $30 \mathrm{~min}$ during the $240 \mathrm{~min}$ of exposure to squamocin and transferred to $4 \%$ paraformaldehyde in $0.1 \mathrm{M}$ sodium phosphate buffer $\mathrm{pH} 7.2$ for $24 \mathrm{~h}$. The larvae were dehydrated in a graded ethanol series and embedded in resin JB4. The slices of $4 \mu \mathrm{m}$ thickness were stained with hematoxyline and eosin (HE) and analyzed under a light microscope.

The controls comprised $20 \mathrm{~A}$. aegypti third-instar larvae exposed to $25 \mathrm{~mL}$ of vehicle Tween 20 . 


\section{Conclusions}

The larvicidal activity, disruption of the peritrophic membrane, alteration in the structure of the digestive cells, brush border injury, large areas of cytoplasmic vacuolation and cytoplasmic projections into the midgut lumen, suggested that absorption of squamocin caused cell damages in the midgut followed by the death of $A$. aegypti larvae.

\section{Acknowledgements}

The authors would like to thank the "Conselho Nacional de Desenvolvimento Científico e Tecnológico (CNPq), Coordenação de Aperfeiçoamento de Pessoal de Nível Superior (CAPES), Fundação de Amparo à Pesquisa do Estado de Minas Gerais (FAPEMIG).

\section{Author Contributions}

Marilza S. Costa, Mônica J. B. Pereira, José Eduardo Serrão conceive and designed the experiments. Marilza S. Costa, Jamile F. S. Cossolin, Milena D. Lima performed the experiments and analyzed the data. Antônio E. G. Sant'Ana contributes with reagents and analysis tools. Marilza S. Costa, José C. Zanuncio, José Eduardo Serrão wrote the paper.

\section{Conflicts of interest}

Authors declare no conflict of interest.

\section{References}

1. Alali, F.Q.; Liu, X.; Mclaughlin, J. Annonaceous acetogenins, recent progress. J. Nat. Prod. 1999, $62,504-540$.

2. Fang, X.P.; Rueser, M.J.; Gu, Z.M.; Zhao, G.X.; Mclaughin, J.L. Annonaceous acetogenins, Na update review. Phytochem. Anal. 1993, 1, 27-48.

3. Rupprecht, J.K.; Hui, Y.H.; Mclaughlin, J.L. Annonaceous acetogenins: A review. J. Nat. Prod. 1990, 53, 233-278.

4. Liaw, C.C.; Wu, T.Y.; Chang, F.R.; Wu, Y.C. Historic perspectives on Annonaceous acetogenins from the chemical bench to preclinical trials. Planta Med. 2010, 76, 1390-1404.

5. Chen, Y.; Xu, S.; Chen, J.W.; Wang, Y.; Xu, H.; Fan, N.; Li, X. Anti-tumor activity of Annona squamosa seeds extract containing annonaceous acetogenin compounds. J. Ethnopharmacol. 2012, $142,462-466$.

6. Mclaughlin, J.L. Paw Paw and cancer: Annonaceous acetogenins from discovery to commercial products. J. Nat. Prod. 2008, 71, 1311-1321.

7. Chen, Y.; Chen, J.W.; Li, X. Cytotoxic bistetrahydrofuran annonaceous acetogenins from the seeds of Annona squamosa. J. Nat. Prod. 2011, 74, 2477-2481.

8. Isman, M.B. Botanical insecticides, deterrents, and repellents in modern agriculture and an increasingly regulated world. Annu. Rev. Entomol. 2006, 51, 45-66. 
9. Pandey, N.; Barve, D. Antioxidant activity of ethanolic extract of Annona squamosa Linn Bark. Int. J. Biomed. Pharma. Sci. 2011, 2, 1692-1697.

10. Costa, M.S.; Pinheiro, D.O.; Serrão, J.E.; Pereira, M.J.B. Morphological changes in the midgut of Aedes aegypti L. (Diptera, Culicidae) larvae following exposure to an Annona coriacea (Magnoliales, Annonaceae) extract. Neotrop. Entomol. 2012, 41, 311-314.

11. Dholvitayakhun, A.; Cushnie, T.P.T.; Trachoo, N. Antibacterial activity of three medicinal Thai plants against Campylobacter jejuni and other foodborne pathogens. Nat. Prod. Res. 2012, 26, 356-363.

12. Londerhausen, M.; Leicht, W.; Lieb, F.; Moeschler, H.; Weiss, H. Molecular mode of action of annonins. Pestic. Sci. 1991, 33, 427-438.

13. Martin, J.M.; Madigosky, S.R.; Gu, Z.; Zhou, D.; Wu, J.; Mclaughlin, J.L. Chemical defense in the zebra swallowtail butterfly, Eurytides marcellus, involving annonaceous acetogenins. $J$. Nat. Prod. 1999, 62, 2-4.

14. Guadaño, A.; Gutiérrez, C.; Peña, E.; Cortes, D.; González-Coloma, A. Insecticidal and mutagenic evaluation of two annonaceous acetogenins. J. Nat. Prod. 2000, 63, 773-776.

15. Álvarez, O.C.; Barrachina, I.; Ayala, I.M.; Gonzalez, M.C.M.; Moya, P.S.; Neske, A.; Bardon, A. Toxic effects of annonaceous acetogenins on Oncopeltus fasciatus. J. Pest Sci. 2008, 81, 85-89.

16. Blessing, L.D.T.; Ramos, J.; Diaz, S.; Altabef, A.B.; Bardón, A.; Brovetto, M.; Seoane, G.; Neske, A. Insecticidal properties of annonaceous acetogenins and their analogues. Interaction with lipid membranes. Nat. Prod. Commun. 2012, 7, 1215-1218.

17. Gypser, A.; Billow, C.; Scharf, H.D. Determination of the absolute configuration of Annonin I, a bioactie natural acetogenin from Annona squamosa. Tetrahedron Lett. 1995, 51, 1921-193.

18. Peter, N.; Cautain, B.; Melguizo, A.; Vicente, F.; Genilloud, O.; Peláez, F.; Tormo, J.R. Mitochondrial complex I inhibitors, acetogenins, induce HepG2 cell death through the induction of the complete apoptotic mitochondrial pathway. J. Bioenerg. Biomembr. 2013, 45, 153-164.

19. Lümmen, P. Complex I inhibitors as insecticides and acaricides. Biochim. Biophys. Acta 1998, 1364, 287-296.

20. Takada, M.; Kuwabara, K.; Nakato, H.; Tanaka, A.; Iwamura, H.; Miyoshi, H. Definition of crucial structural factors of acetogenins, potent inhibitors of mitochondrial complex I. Biochim. Biophys. Acta 2000, 1460, 302-310.

21. Pardhasaradhi, B.V.V.; Reddy, M.; Ali, A.M.; Kumari, A.L.; Khar, A. Differential cytotoxic effects of Annona squamosa seed extracts on human tumour cell lines: Role of reactive oxygen species and glutathione. J. Biosci. 2005, 30, 237-244.

22. Alves, S.N.; Serrão, J.E.; Melo, A.L. Alterations in the fat body and midgut of Culex quinquefasciatus larvae following exposure to different insecticides. Micron 2010, 41, 592-597.

23. Correia, A.A.; Teixeira, V.W.; Teixeira, A.A.C.; Oliveira, J.V.; Torres, J.B. Morfologia do canal alimentar de lagartas de Spodoptera frugiperda (JE Smith) (Lepidoptera, Noctuidae) alimentadas com folhas tratadas com nim. Neotrop. Entomol. 2009, 38, 83-91.

24. Ray, K.; Mercedes, M.; Chan, D.; Choi, C.; Nishiura, J.T. Growth and differentiation of the larval mosquito midgut. J. Insect Sci. 2009, 9, 55-68. 
25. Gusmão, D.S.; Páscoa, V.; Mathias, L.; Curcino, V.I.J.; Braz-Filho, R.; Alves, L.F.J. Derris (Lonchocarpus) urucu (Leguminosae) extract modifies the peritrophic matrix structure of Aedes aegypti (Diptera: Culicidae). Mem. Inst. Oswaldo Cruz 2002, 97, 371-375.

26. Jewess, P.J.; Devonshire, A.L. Kinetic microplate-based assays for inhibitors of mitochondrial NADH: Ubiquinone oxidoreductase (complex I) and succinate: Cytochrome $c$ oxidoreductase. Anal. Biochem. 1999, 272, 56-63.

27. Cortes, D.; Myint, S.H.; Harmange, J.C.; Sahpz, S.; Figadere, B. Catalytic hydrogenation of Annonaceous acetogenins. Tetrahedron Lett. 1992, 33, 5225-5226.

28. Sahai, M.; Singh, S.; Singh, M.; Gupta, Y.K.; Akashi, S.; Yuji, R.; Hirayama, K.; Asaki, H.; Araya, H.; Hara, N.; et al. Annonaceous acetogenins from the seeds of Annona squamosa adjacent bis-tetrahydrofuranic acetogenins. Chem. Pharm. Bull. 1994, 42, 1163-1174.

29. Barrachina, I.; Royo, I.; Baldoni, H.A.; Chahboune, N.; Suvire, F.; Depedro, N.; Zafra-Polo, M.C.; Bermejo, A.; El Aouad, N.; Cabedo, N.; et al. New antitumoral acetogenin 'Guanacone type' derivatives, isolation and bioactivity. Molecular dynamics simulation of diacetyl-guanacone. Bioorg. Med. Chem. 2007, 15, 4369-4381.

30. Blessing, L.D.T.; Álvarez-Colon, O.; Popich, S.; Neske, A.; Bardón, A. Antifeedant and toxic effects of acetogenins from Annona montana on Spodoptera frugiperda. J. Pest Sci. 2010, 83, 307-310.

31. Bombasaro, J.A.; Blessing, L.D.T.; Diaz, S.; Neske, A.; Suvire, F.D.; Enriz, R.D.; Rodríguez, A.M. Theoretical and experimental study of the interactions of Annonaceous acetogenins with artificial lipid bilayers. J. Mol. Struct. 2011, 1003, 87-91.

32. Shimada, H.; Kozlowski, J.F.; Mclaughlin, J.L. The localizations in liposomal membranes of the tetrahydrofuran ring moieties of the annonaceous acetogenins, annonacin and sylvaticin, as determined by ${ }^{1}$ HNMR spectroscopy. Pharmacol. Res. 1998, 37, 357-363.

(C) 2014 by the authors; licensee MDPI, Basel, Switzerland. This article is an open access article distributed under the terms and conditions of the Creative Commons Attribution license (http://creativecommons.org/licenses/by/3.0/). 